Voix et Images

voixetimages

\title{
Papineau et son temps, de Robert Rumilly
}

\section{Jean-Paul Bernard}

Volume 4, numéro 1, septembre 1978

Rina Lasnier

URI : https://id.erudit.org/iderudit/200142ar

DOI : https://doi.org/10.7202/200142ar

Aller au sommaire du numéro

Éditeur(s)

Les Presses de l'Université du Québec

ISSN

0318-9201 (imprimé)

1705-933X (numérique)

Découvrir la revue

Citer ce compte rendu

Bernard, J.-P. (1978). Compte rendu de [Papineau et son temps, de Robert

Rumilly]. Voix et Images, 4(1), 141-143. https://doi.org/10.7202/200142ar d'utilisation que vous pouvez consulter en ligne.

https://apropos.erudit.org/fr/usagers/politique-dutilisation/ 


\section{Papineau et son temps ${ }^{1}$, de Robert Rumilly}

Déjà, en 1934, Robert Rumilly avait écrit une biographie de Papineau. Plus de quarante ans plus tard, l'année dernière, il publiait chez Fides un gros ouvrage en deux volumes sous le titre de Papineau et son temps. Entre les deux moments il avait trouvé le moyen de faire paraître non seulement les quarante et un volumes de son Histoire de la province de Québec mais aussi nombre d'autres travaux, dont Maurice Duplessis et son temps et une Histoire de Montréal en cinq volumes. L'ensemble a de quoi impressionner, malgré les nombreuses répétitions de l'auteur d'une œuvre à l'autre.

Inlassablement, Monsieur Rumilly dévore sources imprimées, fonds d'archives et vieux journaux et, d'une plume alerte, il cite et reconstitue ce qu'il a trouvé. Pour Papineau et son temps cela donne plus de douze cents pages dans lesquelles le lecteur peut trouver un certain nombre d'informations neuves, et un récit qui distingue souvent mal l'essentiel de l'accessoire. Bien sûr, il y a encore, et il y aura toujours, des défenseurs de cette conception de l'écriture historique. Dans le Devoir du samedi 25 février 1978, Jean Éthier-Blais n'écrit-il pas :

La grande force de M. Robert Rumilly réside en ceci qu'il n'oublie aucune des composantes historiques; il n'aligne pas les colonnes de chiffres pour faire imposant, il n'a pas recours aux balivernes "sociologiques" pour faire savant, il ne déroule pas les théories pour faire profond; tout simplement, il raconte les faits. Le lecteur sait d'instinct où est le vrai et que cela suffit.

Est-il nécessaire de rappeler, avant de passer à Papineau et son temps, que les réflexions sur l'histoire, et sur la littérature, depuis quelques générations, ne vont pas généralement dans ce sens?

Le champ couvert par Rumilly est celui de l'évolution de Louis-Joseph Papineau et de sa famille dans leurs rapports avec leur entourage québécois d'hommes politiques et de clercs. L'auteur donne aussi certains éléments du contexte américain et européen. Mais il faut préciser que, de soi, le genre traditionnel "Tel grand homme et son temps» (Life and Times of...) 
peut toujours conjuguer l'histoire de la carrière de Papineau et celle de la permet mieux de comprendre le héros que son époque. A la limite, on politique bas-canadienne des années 1815-1840. De fait, l'ouvrage de Rumilly est intéressant comme étude des origines et des événements de 18371838. Mais, comme Papineau survit plus de trente ans à son rôle de premier plan, l'intérêt du dernier tiers de l'ouvrage de Rumilly est presque uniquement d'ordre biographique.

L'auteur estime que «toute révolution est une pièce de théâtre... mêlant idéalistes et têtes brûlées ". II explique (?) ainsi le rôle clé joué par la vallée du Richelieu dans l'affrontement armé de 1837 :

Nulle région de la province ne respire à un tel degré l'aisance, l'agrément de vivre. Les travaux domestiques, les services religieux, les réunions, les visites et les bons repas occupent les journées d'hiver. La ménagère tisse l'étoffe nécessaire à l'habillement; le fermier fabrique sa charrette et répare lui-même les harnais. On n'a pas, comme dans les pays arides, de continuelles raisons de s'aigrir. Les Canadiens de ce temps ne connaissent pas - ne toléreraient pas - la harassante ingérence de l'État dans leurs affaires que le socialisme réserve à leurs descendants. Le fisc ne perçoit d'impôt - encore est-il minime - que sur les marchandises importées, dont les habitants à part le rhum de la Jamaïque - usent peu. Avec la dîme et la redevance seigneuriale, le fermier est libre de toutes charges. La privation des libertés politiques ne l'incommode pas.

C'est pourtant là qu'on va mourir pour tenter de rendre le Conseil législatif électif.

On s'en étonnerait si l'on ne savait que les révolutions ne couvent pas forcément, et loin de là, parmi les populations les plus pauvres, qui cherchent plutôt la protection d'un bras fort, d'un dictateur. L'aisance même de la vallée du Richelieu, où les cultivateurs enrichis envoient leurs fils au collège de Montréal pour en faire «des Messieurs »... favorise l'effervescence intellectuelle et politique... Quelques fortes personnalités font le reste.

Parlant, il est vrai, du Haut-Canada, Rumilly écrit que «imputer l'insurrection de 1837 à des causes économiques, suivant une mode d'ailleurs périmée, serait méconnaître les ressorts passionnels qui font agir les hommes». Dans le Bas-Canada comme dans le Haut-Canada le «motif principal de l'agitation" est politique, et, dans le Bas-Canada même, «toute cette fermentation oppose des idéologies, beaucoup plus que des races $"$.

Avec une telle conception du fondement - ou de l'absence de fondement - de l'exaspération, puis du recours à l'illégalité et aux armes, on peut s'étonner de ce que l'auteur paraisse éviter de juger sévèrement l'ensemble du mouvement des patriotes. De fait, il décrit les députés qui suivent Papineau comme une «phalange de jeunes avocats et notaires montréalais, irresponsables... et des cultivateurs sans instruction, vaniteux de leur titre". Chénier est "un exalté sympathique»; Robert Nelson, Côté 
et Chevalier de Lorimier sont des a emportés qui ont tout laissé, femme, enfants, propriété et clientèle, pour se jeter dans la révolution ". Mais Papineau échappe aux épithètes les plus dures. Pourquoi? Dans son cas aussi, Rumilly parle d'utopie... et il va même jusqu'à laisser entendre qu'il y a une ambiguïté, sinon une imposture, à prétendre trop facilement représenter et personnifier le peuple. Mais Papineau a de la classe, c'est-à-dire, à la fois de la fortune, de la culture et de l'influence. Son discours est éblouissant. II est drapé de noblesse et de dignité. Et Rumilly, qui souligne à l'occasion ses limites et ses faiblesses, voire ses mesquineries, traite le grand homme avec ménagement.

Papineau et son temps se situe apparemment en dehors des grandes questions actuelles sur le $19^{\circ}$ siècle québécois et particulièrement sur les événements de 1837 et sur la Confédération. Mais on aurait tort d'estimer neutre ou innocent le « récit» de Monsieur Rumilly du fait que celui-ci évite de rendre compte explicitement de ses conceptions sociales et de son cadre d'analyse. D'ailleurs il suffit de gratter un peu pour découvrir, dans le récit lui-même et dans le non-dit, les positions élitistes et conservatrices de l'auteur. Parce que le récit insiste sur les circonstances de personnes et de caractères, il permet mal d'établir des rapports autres que superficiels aux réalités présentes et aux grandes interrogations du présent. Aussi, l'ouvrage de Monsieur Rumilly est-il condamné à occuper une place mineure dans le débat central qui oppose encore l'œuvre de Maurice Séguin, celle de Fernand Ouellet et celle de Stanley-Bréhaut Ryerson.

Mais il reste qu'il peut être utile de posséder Papineau et son temps et de le consulter à l'occasion, comme on consulte un dictionnaire. 